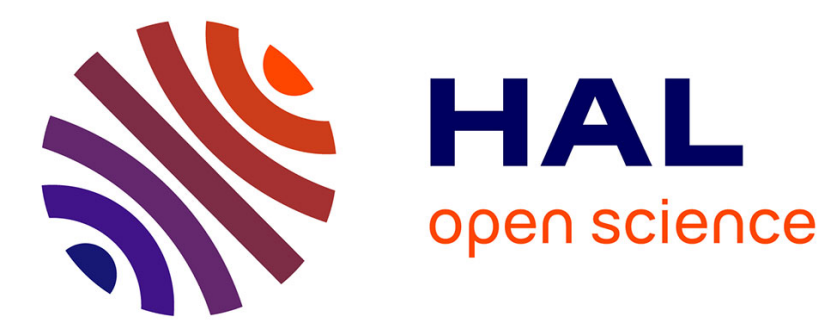

\title{
Nitrogen isotope variations in the solar system
}

Evelyn Füri, Bernard Marty

\section{- To cite this version:}

Evelyn Füri, Bernard Marty. Nitrogen isotope variations in the solar system. Nature Geoscience, 2015, 10.1038/NGEO2451 . hal-01345978

\section{HAL Id: hal-01345978 \\ https://hal.science/hal-01345978}

Submitted on 20 Jul 2016

HAL is a multi-disciplinary open access archive for the deposit and dissemination of scientific research documents, whether they are published or not. The documents may come from teaching and research institutions in France or abroad, or from public or private research centers.
L'archive ouverte pluridisciplinaire HAL, est destinée au dépôt et à la diffusion de documents scientifiques de niveau recherche, publiés ou non, émanant des établissements d'enseignement et de recherche français ou étrangers, des laboratoires publics ou privés. 
Nitrogen isotope variations in the solar system

Evelyn Füri ${ }^{1}$ and Bernard Marty1,*

1 Centre de Recherches Pétrographiques et Géochimiques, CNRS-Université de Lorraine, 15 rue Notre Dame des Pauvres, BP20, 54501 Vandoeuvre-lès-Nancy, France

* Corresponding author e-mail address: bmarty@crpg.cnrs-nancy.fr

The relative proportion of the two isotopes of nitrogen $\left({ }^{14} \mathrm{~N}\right.$ and $\left.{ }^{15} \mathrm{~N}\right)$ shows dramatic variations among the different solar system objects and reservoirs. NASA's

3 Genesis mission, which provided the first direct sample of the solar wind, confirmed

4 that the Sun, and by inference the protosolar nebula, is highly depleted in the heavy ${ }^{15} \mathrm{~N}$

5 isotope. The inner planets, asteroids, and comets are enriched in ${ }^{15} \mathrm{~N}$ by tens to

6 hundreds of percent, with organic matter in primitive meteorites recording the most

7 extreme ${ }^{15} N /{ }^{14} N$ ratios. Several lines of evidence suggest that these ${ }^{15} \mathrm{~N}$ enrichments

8 were not inherited from presolar material but are, instead, the result of $\mathrm{N}$ isotope

9 fractionation processes that occurred early in solar system history. Together, these

10 observations indicate that $\mathbf{N}$ isotopes are a powerful tool to investigate early material

11 processing and large-scale disk dynamics as well as planetary formation processes. In

12 addition, $\mathbf{N}$ isotopes are the tracer of choice to investigate the origin and evolution of

13 planetary atmospheres.

The solar system formed when a fraction of a dense molecular cloud collapsed and a

16 central star, the proto-Sun, started burning its nuclear fuel ${ }^{1}$. The surrounding disk made of gas

17 and dust, the protosolar nebula (PSN), was thoroughly stirred and homogenized due to large-

18 scale heating and mixing driven by loss of the angular momentum, the energy delivered by the

19 proto-Sun, and magneto-rotational turbulence. The efficiency of these processes is evident in

20 primitive ("carbonaceous") meteorites, which show a remarkable homogeneity in the isotopic

21 compositions of their constituents down to the part per million level for most elements of the 
22 periodic table ${ }^{2}$. Relics of the initial heterogeneous mixture of stellar debris can only be found in

23 nano-to-micron-sized presolar grains that were thermally resistant enough to survive high

24 enthalpy processing 3 . However, the light elements hydrogen, carbon, nitrogen, and oxygen,

25 show significant, sometimes extreme, isotope variations among solar system objects and

26 reservoirs, from a few percents for $\mathrm{C}$ and $\mathrm{O}$, to tens or even hundreds of percents for $\mathrm{H}$ and $\mathrm{N}$

27 (ref. 4). These light elements, by far the most abundant ones in the PSN, share the property to

28 have been predominantly in the gaseous state $\left(\mathrm{H}_{2}, \mathrm{CO}, \mathrm{N}_{2}\right.$, etc., and their ionized derivatives) in

29 the presolar cloud and in the disk. Consequently, they were prone to efficient isotope exchange

30 and interactions with stellar photons and cosmic rays, either in the interstellar medium (ISM) ${ }^{5}$,

31 or in the presolar cloud or the PSN (e.g., refs. 4,6). Thus, these isotope compositions convey a

32 unique record of solar system forming processes.

33 The largest isotope variations are observed for hydrogen and nitrogen. The

34 deuterium/hydrogen $(\mathrm{D} / \mathrm{H})$ ratio varies by a factor of $\sim 35$, from the PSN value of $21 \pm 0.5 \times 10^{-6}$

35 (ref. 7) to D-rich "hotspots" in meteorites with values up to $720 \times 10^{-6}$ (ref. 8). Inner solar

36 system objects $\left(\sim 150 \times 10^{-6}\right.$; ref. 7$)$ and comets $\left(150-500 \times 10^{-6}\right.$; refs. 9-11) show intermediate

37 values, and possibly define an increase of the $\mathrm{D} / \mathrm{H}$ ratio with heliocentric distance. A consistent

38 scheme emerges in which nebular $\mathrm{H}_{2}$ poor in deuterium exchanged isotopically with $\mathrm{H}_{2} \mathrm{O}$ at

39 low temperature, resulting in a preferential D-enrichment of the latter. Deuterium-rich water

40 then froze out onto icy grains and exchanged isotopically with organics and silicates as a result

41 of turbulent transport and aqueous alteration on forming planetesimals ${ }^{12}$. Although this

42 scenario is not without weaknesses and is still a matter of debate, the $\mathrm{D} / \mathrm{H}$ isotopic tracer

43 offers the possibility to investigate the relationships between the different solar system

44 reservoirs. In particular, it is central in the debate on the origin of water (cometary or 45 asteroidal) in the inner solar system including the oceans ${ }^{10}$. 
The relative proportion of the two stable isotopes of nitrogen, ${ }^{14} \mathrm{~N}$ and ${ }^{15} \mathrm{~N}$, also shows

47 outstanding variability in the solar system. For expressing the $\mathrm{N}$ isotope composition,

48 geochemists and cosmochemists use the stable isotope delta notation:

$$
\delta^{15} \mathrm{~N}=\left[\left({ }^{15} \mathrm{~N} /{ }^{14} \mathrm{~N}\right)_{\text {sample }} /\left({ }^{15} \mathrm{~N} /{ }^{14} \mathrm{~N}\right){ }_{\text {standard }}-1\right] \times 1,000
$$

50 where $\delta^{15} \mathrm{~N}$ expresses the deviation of the sample ratio relative to a standard in parts per

51 mil (\%o). The nitrogen standard is the isotope composition of atmospheric $\mathrm{N}_{2}\left({ }^{15} \mathrm{~N} /{ }^{14} \mathrm{~N}=3.676\right.$

$52 \times 10^{-3}$; ref. 13). On Earth, most variations are of the order of a few to tens of permil (e.g., ref.

53 14). Because the range of extraterrestrial $\mathrm{N}$ isotope variations can be much larger than the

54 permil level, cosmochemists use instead the absolute value of the ${ }^{15} \mathrm{~N} /{ }^{14} \mathrm{~N}$ ratio, following the

55 stable isotope convention that the rare, heavy isotope is the numerator. To complicate matters

56 further, astronomers and astrophysicists use instead the ${ }^{14} \mathrm{~N} /{ }^{15} \mathrm{~N}$ notation (272 for air)

57 (despite using the $\mathrm{D} / \mathrm{H}$ notation for hydrogen as do cosmochemists). Both notations are given

58 here for the sake of better understanding by these communities.

59 On Earth, the $\mathrm{N}$ isotope composition varies by no more than $2 \%$, but variations can reach $60500 \%$ on a solar system scale (Figs. 1 and 2). Until recently, the causes of this variability were

61 not understood, for two main reasons. Firstly, the solar system initial ${ }^{14} \mathrm{~N} /{ }^{15} \mathrm{~N}$ ratio was 62 unknown. Secondly, nitrogen isotopes are more difficult to quantify than hydrogen isotopes

63 because they are generally less abundant in cosmochemical material, and because they are 64 difficult to measure at distance by spectroscopic methods. The analysis of solar wind ions 65 returned to Earth by the Genesis mission - together with advances in high-spatial-resolution, 66 high-sensitivity isotope analysis in the laboratory as well as in high-resolution UV 67 spectroscopy (Box 1) - have permitted major leaps of understanding in the cosmochemistry of 68 this element. Here, we review recent advances in the domain that are particularly relevant in 69 the context of the measurements currently carried out on Comet 67P/Churyumov70 Gerasimenko by the Rosetta spacecraft instruments. 


\section{Nucleosynthesis of $\mathbf{N}$ isotopes and galactic evolution}

73 The production paths and rates of nitrogen isotopes are not fully understood ${ }^{15-17} \cdot{ }^{14} \mathrm{~N}$ is

74 produced during the cold CNO cycle in low to intermediate mass stars $\left(\mathrm{M}_{\text {solar }}<\mathrm{M}<7 \mathrm{M}\right.$ solar $)$ and

75 is released to the interstellar medium by dredge-up events during asymptotic giant branch

76 (AGB) phases that terminate the lives of most stars ("secondary" production, i.e., not produced

77 directly from $\mathrm{H}$ and He nuclei). This isotope is also produced in the so-called hot CNO cycle that

78 takes place in massive stars turning into AGBs during dredge-up from the carbon layer

79 ("primary" production from 3 alpha particles and two protons). ${ }^{15} \mathrm{~N}$ is destroyed in the cold

80 CNO cycle, requiring other mechanisms such as ${ }^{15} \mathrm{~N}$ production during the hot CNO cycle in

81 novae and, possibly, neutrino spallation on ${ }^{16} 0$ in type II supernovae, both productions being

82 "secondary". Consequently, a nucleosynthetic isotope composition cannot be predicted from

83 theory, and estimates for the $\mathrm{N}$ isotope production in the galaxy rely on (limited) observations.

84 In molecular clouds, the $\mathrm{N}$ isotope composition is mainly measured in $\mathrm{CN}, \mathrm{HCN}, \mathrm{HNC}$, and,

85 more recently, in $\mathrm{NHD}^{+}$molecules ${ }^{17-22}$. For molecular $\mathrm{N}_{2}$, the signal-to-noise ratio is too low for

86 a spectroscopic measurement. The data seem to define an isotope gradient with a decrease of

$87{ }^{15} \mathrm{~N}$ relative to ${ }^{14} \mathrm{~N}$ with increasing distance from the galaxy center (Fig. 1; refs. 17,18). Because

88 stars in the galaxy center tend to be more metal-rich (metallicity being here the proportion of

89 elements heavier than helium), secondary production of ${ }^{15} \mathrm{~N}$ that presumably takes place in

90 novae and supernovae should decrease more rapidly with galactocentric distance than the

91 primary component of ${ }^{14} \mathrm{~N}$ production, in qualitative agreement with the observation (Fig. 1).

92 Strikingly, the solar system, represented by the PSN value (see next subsection), does not fit

93 the correlation. The observed offset could result from a localized $\mathrm{N}$ isotope evolution since the

94 solar system isolated nitrogen from the local ISM $4.56 \mathrm{Ga}$ ago. However, a ${ }^{14} \mathrm{~N} /{ }^{15} \mathrm{~N}$ value of $~$

$95 \geq 400$ has been proposed for the local ISM $^{23}$ where the Sun was born, consistent with the solar

96 ratio and implying little $\mathrm{N}$ isotope evolution with time. Alternatively, the apparent anomaly

97 may be explained by the uncertainty in the data defining the correlation depicted in Fig. 1. CN 
or HCN, the molecules for which the nitrogen isotopic compositions are measured in dense

99 cores, could have been isotopically fractionated with respect to the source composition, and

100 may not be representative of the local ISM values. Indeed, measurements of the $\mathrm{N}$ isotope

101 compositions in three starless dense cores of the local ISM, either in $\mathrm{NH}_{3}-\mathrm{NH}^{+}$(refs. 20-22) or

102 in $\mathrm{HCN}$, suggest that the nitrile formation path (leading to $\mathrm{HCN}$ and $\mathrm{CNH}$ ) drastically enriches

$103{ }^{15} \mathrm{~N}$ compared to the amine path (NH compounds) (Fig. 2; ref. 19).

104 Remarkably, the order of magnitude variation of the nitrogen isotope composition in the

105 solar system, defined by the most ${ }^{15} \mathrm{~N}$-rich portion of the Isheyevo meteorite ${ }^{24}$ and the 106 protosolar nebula composition (Figs. 1 and 2; see subsection below), is comparable to the

107 range of values measured in galactic molecular clouds all over the galaxy (Fig. 1). A 108 straightforward interpretation would be that the solar system contains isotopically

109 heterogeneous, nucleosynthetic nitrogen components inherited from ISM. However, other 110 isotope systems do not show correlated isotope variations. For example, nitrogen's "brother"

111 element carbon, whose two stable isotopes ${ }^{12} \mathrm{C}$ and ${ }^{13} \mathrm{C}$ are produced in different 112 nucleosynthetic pathways as well and also show a diversity of isotopic compositions among

113 molecular clouds, displays a near-constant isotopic composition in the solar system within $\sim 10$

$114 \%$ (ref. 25). The isotope variations of nitrogen in the solar system are therefore unlikely to

115 represent remnants of nucleosynthetic heterogeneities, and are instead attributed to isotope

116 fractionation. The nature of the fractionating processes (e.g., interactions with solar/stellar

117 photons vs. low temperature isotope exchange) are still debated (Boxes 2 and 3).

\section{The protosolar nebula}

120 The $\mathrm{N}$ isotope analysis of Jupiter's atmosphere by spectroscopy $\left({ }^{14} \mathrm{~N} /{ }^{15} \mathrm{~N}=526_{-169}^{+585}, \delta^{15} \mathrm{~N}=-\right.$ $121483_{-272}^{+245} \%$; ref. 26$)$ and by in-situ mass spectrometry $\left({ }^{14} \mathrm{~N} /{ }^{15} \mathrm{~N}=435 \pm 60, \delta^{15} \mathrm{~N}=-375 \pm 80 \%\right.$; 122 ref. 27) suggested a ${ }^{15} \mathrm{~N}$-poor solar nitrogen composition. Independently, a ${ }^{14} \mathrm{~N} /{ }^{15} \mathrm{~N}$ ratio of $123428 \pm 8\left(\delta^{15} \mathrm{~N}=-364 \pm 12 \%\right.$ ) has been obtained for a rare TiN (osbornite) phase within a 
124 calcium-aluminum-rich inclusion (CAI) (ref. 28). Because osbornite was presumably the first

125 solid N-bearing phase to condense from the PSN, this value was concluded to correspond to the

126 PSN signature at the time of solid condensation.

127 At present, the isotopic composition of the PSN is best represented by that of the Sun, 128 which concentrates more than $99 \%$ of the mass of the solar system. For the isotope analysis of

129 the Sun, only the solar wind (SW; the corpuscular emission of the Sun which consists of matter 130 from the solar convective zone, ionized in the photosphere and accelerated along open lines of

131 the Sun's magnetic field) is available for sampling. The nitrogen isotope composition of the 132 modern solar wind was recently measured directly thanks to NASA's Genesis mission 133 (Discovery Program) ${ }^{29}$. The Genesis spacecraft sampled the SW during 27 months at the 134 Lagrangian point L2 and returned SW-irradiated material for laboratory analysis in 2004.

135 Despite a hard landing (the parachute failed to open), the SW-implanted target material could 136 be analyzed by two different extraction techniques for $\mathrm{N}$ isotopes (laser ablation-static mass 137 spectrometry ${ }^{30}$ and ion probe ${ }^{31}$ ). Both methods gave consistent results that permitted to define 138 the PSN nitrogen isotope composition of ${ }^{14} \mathrm{~N} /{ }^{15} \mathrm{~N}=441 \pm 5\left(\delta^{15} \mathrm{~N}=-383 \pm 8 \%\right.$; ref. 31$)$, after 139 moderate $(24 \%)$ correction for isotope fractionation in solar processing. Because the modern 140 solar wind has a $\mathrm{N}$ isotope composition very close to that of Jupiter and osbornite, this 141 comparison confirms that the Sun did neither synthezise N nor significantly fractionate N 142 isotopes by more than about $3 \%$ from its birth to present-day. The PSN value constitutes the 143 anchor value to which to compare other nitrogen isotope signatures of solar system objects 144 (Fig. 2).

146 The surface of the Moon

147 The surface of the Moon, which lacks atmospheric shielding and full magnetic field 148 protection, has accumulated SW ions for hundreds of millions of years. The analysis of SW, 149 either implanted into aluminum foils during the visits by the Apollo astronauts or in the lunar 
150 soils that were recovered, was a science priority of the Apollo and Luna programs. One of the

151 most intriguing results of the lunar exploration was the discovery of a $\sim 30 \% \mathrm{~N}$ isotope

152 variation in lunar soils and rocks ${ }^{32,33}$, one order of magnitude larger than that on Earth.

153 Spallation by cosmic rays that produces ${ }^{15} \mathrm{~N}$ from ${ }^{16} \mathrm{O}$ can account for some of the low ${ }^{14} \mathrm{~N} /{ }^{15} \mathrm{~N}$

154 values but fails to explain the occurrence of light ( ${ }^{15} \mathrm{~N}$-poor) nitrogen on the Moon. Noble gases

155 in lunar soils are mostly derived from $\mathrm{SW}^{34}$, so that lunar nitrogen was assumed to be solar as

156 well. Thus, prior to the Genesis mission, the $\mathrm{N}$ isotope variations, which seemed to relate to the

157 epoch of soil exposure, were attributed to secular changes in the isotopic composition of the

158 SW33,35. This possibility, however, faced serious difficulties: no nucleosynthetic process within

159 the Sun capable of changing the $\mathrm{N}$ isotope composition could be identified ${ }^{36}$, and comparison

160 with carbon (whose isotope composition in lunar samples varies much less than that of

161 nitrogen; ref. 25) and helium (whose isotope composition in lunar soils appears constant over

162 time; ref. 37) implied a negligible secular evolution of the SW. Finally, the development of

163 coupled noble gas-nitrogen isotope analysis - together with the Genesis findings -

164 demonstrated that, contrary to noble gases, an additional, non-SW nitrogen component is

165 present in lunar soils ${ }^{38-40}$. The conjoint measurement of $\mathrm{H}$ and $\mathrm{N}$ isotope variations through the

166 outer skin of lunar soil grains with an ion probe (Box 1; ref. 41) revealed that ${ }^{15} \mathrm{~N}$-depleted SW-

$167 \mathrm{~N}\left({ }^{14} \mathrm{~N} /{ }^{15} \mathrm{~N}>340, \delta^{15} \mathrm{~N}<-200 \%\right)$ is mixed to a variable extent with "heavy" ( $\left.{ }^{15} \mathrm{~N}-\mathrm{rich}\right)$ nitrogen.

168 The $N$ isotope signature of the non-solar end-member $\left({ }^{14} \mathrm{~N} /{ }^{15} \mathrm{~N}=265 \pm 5 ; \delta^{15} \mathrm{~N}=50-100 \% 0\right)$ is

169 consistent with delivery of asteroidal, rather than cometary, material to the lunar surface, with

170 a flux comparable to that of interplanetary dust and micrometeorites on Earth, after scaling to

171 different gravitational focusing and surface areas of the two planetary bodies 39,40 . An

172 alternative interpretation is that the ${ }^{15} \mathrm{~N}$-rich component is supplied by an "Earth wind" flux of

173 terrestrial atmospheric nitrogen ${ }^{42}$. Early in the history of the Earth-Moon system, before the

174 development of the global geomagnetic field, interaction of the SW with Earth's upper

175 atmosphere may have resulted in a significant $\mathrm{N}^{+}$escape flux. However, since the Moon is 
176 tidally locked to Earth, the Earth wind contribution is expected to be absent on the lunar

177 farside. Future sampling may permit to distinguish between an asteroidal or terrestrial origin

178 of the ${ }^{15} \mathrm{~N}$ enrichment. Hence, the lunar surface constitutes a superb opportunity to investigate

179 the nature and flux of matter and ions delivered to planetary surfaces through time, and will

180 certainly deserve further attention in future lunar missions aimed at investigating the origin of

181 volatile elements (e.g., water) in the inner solar system.

182

\section{Planets, asteroids and comets}

184 The atmospheres of Jupiter ${ }^{26,27}$ and Saturn ${ }^{43}$ are as ${ }^{15} \mathrm{~N}$-depleted as the PSN. Thus, they 185 may represent remnants of the PSN gas, either trapped gravitationally during planetary growth 186 or inherited from accretion of icy bodies ${ }^{44}$. The second possibility implies that these icy 187 planetesimals had a solar-like $\mathrm{N}$ isotope composition and were not as ${ }^{15} \mathrm{~N}$-rich as are present188 day comets (see below).

189 The inner planets - Earth and Moon ${ }^{45}$, as well as the interior of Mars ${ }^{46}$ and the atmosphere 190 of Venus ${ }^{47}$ - are richer in ${ }^{15} \mathrm{~N}$ than solar $\mathrm{N}$ by approximately $60 \%$, and have comparable $\mathrm{N}$

191 isotope compositions on the scale of solar system variations (Fig. 2). In primitive meteorites, 192 nitrogen is mostly hosted in organics, particularly in insoluble organic matter (IOM) and, under 193 reducing conditions, in nitrides. Carbonaceous chondrites, which are rich in volatile elements 194 as their name implies, contain of the order of 1,000 ppm N, with bulk $\mathrm{N}$ isotope compositions 195 within $5 \%$ of the terrestrial value ${ }^{48-50}$. An exception is the CR carbonaceous chondrite clan, 196 whose members are richer in ${ }^{15} \mathrm{~N}$ by up to $25 \%$ (e.g., ref. 51), and a few meteorites defining the 197 CB-CH group that present bulk ${ }^{15} \mathrm{~N}$ enrichments up to $100-150 \%$ (refs. 52,53). The causes of 198 these enrichments are unclear and could be related to impacts between asteroidal bodies and 199 volatile- and/or organic-rich objects rich in ${ }^{15} \mathrm{~N}$ (refs. 51,54). One member of this ${ }^{15} \mathrm{~N}$-rich 200 group, the Isheyevo meteorite, presents so-called "15 $\mathrm{N}$ hotspots" (ref. 55), measured on a 201 micron scale by ion probe ${ }^{24,56}$, characterized by the most extreme ${ }^{15} \mathrm{~N}$ enrichments found in the 
solar system, up to about $450 \%\left({ }^{14} \mathrm{~N} /{ }^{15} \mathrm{~N} \sim 50 ; \delta^{15} \mathrm{~N} \sim 4,500 \%\right.$; ref. 24$) .{ }^{15} \mathrm{~N}$-rich hotspots are

203 typically found in IOM of primitive meteorites ${ }^{57}$ and interplanetary dust particles ${ }^{58}$ (which are

204 small $[\leq 50 \mu \mathrm{m}]$ volatile-rich grains snowing onto Earth's surface, and some of which are

205 probably cometary), as well as in nano-sized globules of the Tagish Lake meteorite ${ }^{59}$. Since IOM

206 shows systematically higher ${ }^{15} \mathrm{~N}$ contents than bulk meteorites and inner planets, ${ }^{15} \mathrm{~N}$-rich

207 nitrogen hosted by organic molecules within dust grains must have been mixed with ${ }^{15} \mathrm{~N}$-poor

$208 \mathrm{PSN} \mathrm{N}_{2}$ to match bulk values ${ }^{30,31}$.

209 Cometary matter was analyzed on Earth thanks to NASA's Stardust mission (Discovery

210 program), which succeeded in collecting grains from a Jupiter family comet (JFC) named

211 81P/Wild2 in 2004, and in returning them to Earth two years later for laboratory analyses ${ }^{60,61 .}$

212 As a result of the high velocity collection, ices were lost during recovery, and only

213 silicate/metal grains survived. Analyses showed that cometary dust is derived from precursors

214 that share mineralogical and isotopic similarities with carbonaceous chondrites, consistent

215 with models advocating large-scale radial mixing in the nascent solar system ${ }^{60-62} \cdot{ }^{15} \mathrm{~N} /{ }^{14} \mathrm{~N}$

216 ratios are also comparable to the values found in meteorites, and excesses of ${ }^{15} \mathrm{~N}$ typical of

217 cometary values (see below) are not observed in bulk analyses ${ }^{63}$, probably because such

218 excesses are hosted by cometary ice $\left(\mathrm{CN}, \mathrm{HCN}, \mathrm{NH}_{3}\right)$ that was lost during Stardust collection.

219 On a smaller scale, ${ }^{15} \mathrm{~N}$-rich hotspots with a maximum $\delta^{15} \mathrm{~N}$ value of $1300 \pm 400 \%$ are

220 observed, similar to the highest values found in IOM and IDPs ${ }^{62}$. Several presolar grains have

221 been identified showing much larger $\mathrm{C}$ and $\mathrm{N}$ isotope variations (from +60 to $+964 \%$ for $\delta^{13} \mathrm{C}$,

222 and from -518 to $-350 \%$ for $\delta^{15} \mathrm{~N}$; ref. 62 ).

223 Additional cometary $\mathrm{N}$ isotope data are from radio and optical spectroscopic observations

224 of $\mathrm{CN}, \mathrm{HCN}$, and $\mathrm{NH}_{2}$ (the latter presumably derived from the photodissociation of $\mathrm{NH}_{3}$ ) ${ }^{64-68}$.

225 Measurements are challenging due to spectroscopic interferences and low abundances of the

226 analyzed molecules, so that data have significant uncertainties compared to laboratory

227 measurements (Box 1). All data collected to date indicate no systematic difference in the 
${ }^{14} \mathrm{~N} /{ }^{15} \mathrm{~N}$ ratio between these different molecules within uncertainties: The mean ${ }^{14} \mathrm{~N} /{ }^{15} \mathrm{~N}$ ratios

229 of CN (18 comets), $\mathrm{HCN}\left(1\right.$ comet), and $\mathrm{NH}_{2}$ (3 comets) are $148 \pm 6\left(\delta^{15} \mathrm{~N}=840 \pm 75 \% 0\right), 139 \pm 26$

$230\left(\delta^{15} \mathrm{~N}=650 \pm 400 \% 0\right)$, and $\sim 140 \pm 40\left(\delta^{15} \mathrm{~N}=940 \pm 500 \% 0\right)$, respectively (Fig. 2). Furthermore,

231 short- and long-period comets seem to have comparable $\mathrm{N}$ isotope compositions. Long-period

232 comets are thought to come from the Oort Cloud (OC comets), whose population is attributed

233 to scattering of icy bodies originally located within the Uranus-Neptune region ${ }^{69,70}$. Short-

234 period comets are proposed to originate from the Kuiper belt reservoir, which is beyond the

235 present-day orbit of Neptune, and/or from the external edge of the disk. Due to gravitational

236 instabilities, some of these icy objects would then have been scattered and injected into the

237 Jupiter region, becoming isotropic (Jupiter Family comets - JFCs). Thus, the available cometary

238 data is inconsistent with a systematic $\mathrm{N}$ isotope variation with heliocentric distance beyond

239 Jupiter. The observation that $\mathrm{NH}_{2}$ on one hand, and $\mathrm{CN}-\mathrm{HCN}$ on the other hand, show similar $\mathrm{N}$

240 isotope signatures is at odds with the prediction of significant nitrogen isotope fractionation

241 between amine and nitrile radicals ${ }^{19}$, unless isotope exchange subsequently erased this effect.

242 It should be emphasized, however, that our knowledge of nitrogen isotopes in cometary

243 material is limited. Depending on the thermal history of these bodies, it is possible that ${ }^{15} \mathrm{~N}$ -

244 poor dinitrogen from the PSN is trapped in ices, and that the bulk $\mathrm{N}$ isotopic composition of

245 comets is de facto unknown. The ROSETTA space mission, which has just started to study

246 comet 67P/Churyumov-Gerasimenko, will hopefully provide for the first time an in-situ

247 inventory of the ${ }^{14} \mathrm{~N} /{ }^{15} \mathrm{~N}$ ratios of different species degassed by the comet.

\section{Conclusions and prospects}

250 The picture that emerges is that there are at least three isotopic reservoirs in the solar

251 system (Fig. 2): i) the PSN, poor in ${ }^{15} \mathrm{~N}\left({ }^{14} \mathrm{~N} /{ }^{15} \mathrm{~N}=441 \pm 5 ; \delta^{15} \mathrm{~N}=-387 \pm 8 \%\right.$ ), ii) the inner solar

252 system, where planets and bulk meteorites are enriched by a factor of 1.6 relative to the PSN

$253\left({ }^{14} \mathrm{~N} /{ }^{15} \mathrm{~N}=272 \pm 15 ; \delta^{15} \mathrm{~N}=0 \pm 50 \%\right.$ ) , and iii) cometary ices, enriched in ${ }^{15} \mathrm{~N}$ by a factor of 3 
254 relative to the $\operatorname{PSN}\left({ }^{14} \mathrm{~N} /{ }^{15} \mathrm{~N}=147 \pm 11 ; \delta^{15} \mathrm{~N}=850 \pm 150 \%\right.$ ). Thus, the distribution of $\mathrm{N}$

255 isotopes in the solar system is roughly consistent with an increase of ${ }^{15} \mathrm{~N}$ enrichments with

256 radial distance from the Sun, in qualitative agreement with the D/H ratio (Fig. B3). However,

257 several lines of evidence demonstrate that a homogeneous, ${ }^{15} \mathrm{~N}$-poor isotope signature initially

258 characterized the solar system, thus requiring a mechanism for the progressive temporal and

259 spatial isotopic evolution. The recent detection of ${ }^{15} \mathrm{~N}$-enriched nitrogen in a CAI, which last

260 interacted with the nebular gas $\leq 0.15 \mathrm{Ma}$ ago as show by the ${ }^{26} \mathrm{Al}-{ }^{26} \mathrm{Mg}$ chronometer, suggests

261 that at least some regions of the disk were driven toward isotopically heavy values very early

262 in solar system history, within the first few tens to hundreds thousands of years after solar

263 system formation ${ }^{71}$. The nature of the fractionating processes is still a matter of debate and

264 several processes might have played a role (Boxes 2 and 3). While some of the D/H vs. ${ }^{15} \mathrm{~N} /{ }^{14} \mathrm{~N}$

265 co-variations are consistent with either kinetic isotope fractionation or ion-molecule reactions,

266 many ${ }^{15} \mathrm{~N}$ excesses are not correlated with enrichments in $\mathrm{D}$, and thus require nitrogen-specific

267 isotope fractionation (Fig. B3). Furthermore, the increase of ${ }^{15} \mathrm{~N}$ enrichments with radial

268 distance from the Sun could have resulted from different types of processes. The interaction

269 rate between the PSN gas and UV photons could have varied with heliocentric distance, with

270 enhanced ${ }^{15} \mathrm{~N}$ fractionation occurring in the outer solar system, where the lower gas density

271 would have allowed deeper photon penetration and/or more efficient freezing out of

272 synthesized molecules than in the denser, hotter inner solar system. It is also possible that

273 several processes were involved: photodissociation by solar photons in the inner solar system,

274 and contribution of $15 \mathrm{~N}$-rich ices formed early in the outer solar system by illumination of

275 ice/dust grains from nearby stars. All these possibilities have profound astrophysical

276 implications and can be tested using nitrogen isotopes, from observation and/or dedicated

277 modeling. Irrespective of the origin(s) of the ${ }^{15} \mathrm{~N}$-enrichment, large-scale turbulence and

278 mixing eventually regionally homogenized material available for planetary accretion, resulting

279 in the isotopic similarity seen for the Earth and most chondritic groups. The same requirement 
280 of efficient isotope fractionation and mixing stands for the outer solar system since all

281 cometary $\mathrm{N}$ analyzed so far is enriched in ${ }^{15} \mathrm{~N}$ by a factor of $\sim 3$ relative to inner planets (Fig. 2).

282 A particularly important question that remains to be addressed with nitrogen isotopes

283 concerns the origin and evolution of the terrestrial atmosphere and oceans. The isotopes of

284 hydrogen do not seem to provide an unambiguous tool for distinguishing between a cometary

285 versus asteroidal origin ever since the discovery of an ocean-like D/H ratio in a comet ${ }^{10}$. So far,

286 all cometary measurements indicate a 3 -fold ${ }^{15} \mathrm{~N}$ enrichment in comets compared to terrestrial

$287 \mathrm{~N}$, suggesting that nitrogen isotopes represent a more powerful tracer than $\mathrm{H}$ isotopes for 288 investigating the origin(s) of planetary atmospheres. Thus, $\mathrm{N}$ isotopes are the tracer of choice 289 to investigate the evolution of planetary atmospheres through time upon thermal and non290 thermal escape processes.

\section{Figure Legends}

294 Figure 1: Nitrogen isotope variation in molecular clouds from our galaxy as a function of

295 distance from the galactic center. Adapted from refs. 17,18. Isotope compositions are given 296 in both absolute ${ }^{14} \mathrm{~N} /{ }^{15} \mathrm{~N}$ ratios and $\delta^{15} \mathrm{~N}$ values (deviation in permil from the atmospheric $297{ }^{15} \mathrm{~N} /{ }^{14} \mathrm{~N}$ ratio). The observed correlation (dashed line; ref. 17) appears consistent with 298 secondary ${ }^{15} \mathrm{~N}$ production in massive stars. The total $\mathrm{N}$ isotope range within the solar system, 299 defined by the most ${ }^{15} \mathrm{~N}$-rich "hotspot" in the Isheyevo meteorite ${ }^{24}$ and the protosolar nebula 300 (PSN) composition ${ }^{31}$, is comparable to that in our galaxy. Error bars indicate $1 \sigma$ 301 uncertainties ${ }^{17}$.

303 Figure 2: Nitrogen isotope variations in solar system objects and reservoirs. The value of 304 the protosolar nebula (PSN) is defined by the measurement of solar wind nitrogen collected by 305 NASA's Genesis mission ${ }^{30,31}$. Except for the Sun, osbornite (TiN) ${ }^{28}$, and the atmospheres of the 
giant planets ${ }^{26,27,43}$, all solar system objects and reservoirs are significantly enriched in ${ }^{15} \mathrm{~N}$

307 compared to the PSN. Values determined for various N species in local and galactic molecular

308 clouds ${ }^{17-22}$ are shown for comparison. Uncertainties of spectroscopic measurements are shown

309 at the $1 \sigma$ level.

311 Figure B1: Nitrogen and hydrogen isotope variations within single lunar grains. a)

312 Silicate grain (breccia 79035 ) showing $\delta^{15} \mathrm{~N}$ values (circles) as low as $-250 \%$ o together with

313 very low $\delta \mathrm{D}$ values (blue squares) at depths $\leq 120 \mathrm{~nm}$. The D-poor hydrogen component (i.e, $\delta \mathrm{D}$

$314 \approx-900 \%$ ) represents implanted SW, highly depleted in deuterium due to D-burning in the Sun.

315 Thus, the low $\delta^{15} \mathrm{~N}$ values give a first-order estimate of the isotopic signature of SW-N. b)

316 Ilmenite grain (soil 71501) containing non-solar N - associated with D-rich (planetary)

317 hydrogen -, which is enriched in ${ }^{15} \mathrm{~N}$ to a similar extent as meteoritic nitrogen. Data from ref.

31841.

Figure B2: Processes leading to a progressive ${ }^{15} \mathrm{~N}-e n r i c h m e n t$ in the solar system.

321 Schematic diagram of the protoplanetary disk made of gas and dust with the proto-Sun at the

322 centre. ${ }^{15} \mathrm{~N}$-enriched ${ }^{15} \mathrm{NH}_{\mathrm{x}}$ (and $\mathrm{C}^{15} \mathrm{~N}$ ) is produced by ion-molecule reactions in the cold 323 regions of the $\operatorname{disk}^{72,73}$ or as a result of photodissociation of $\mathrm{N}_{2}$ by UV light from the proto-Sun

324 or from nearby stars ${ }^{74}$, and is removed from the gas by freezing out and/or trapping in organic 325 matter. (Image of Beta Pictoris; courtesy of NASA).

327 Figure B3: Hydrogen and nitrogen isotope ratios of solar system objects and isotope 328 fractionation processes. Adapted from refs. 75,76. Alpha $\mathrm{H}$ and alpha $\mathrm{N}$ are defined as the $329 \mathrm{D} / \mathrm{H}$ and ${ }^{15} \mathrm{~N} /{ }^{14} \mathrm{~N}$ ratios normalized to the protosolar nebula values $\left([2.1 \pm 0.5] \times 10^{-5}\right.$ (ref. 7$)$ 330 and $[2.27 \times 0.03] \times 10^{-3}$ (ref. 31), respectively). Data and corresponding uncertainties for 331 Moon45,77; Venus47,78; Mars atmosphere ${ }^{79,80}$; chondrites, bulk6,8,50; chondrites, IOM ${ }^{75,81}$; 
332 Isheyevo hotspots ${ }^{24,56}$; Saturn ${ }^{43,82}$; Jupiter ${ }^{27,83}$; Titan atmosphere ${ }^{84}$; comets 66,67,85,86. The

333 observed $\mathrm{H}-\mathrm{N}$ isotope compositions require various isotope fractionation processes.

\section{Box 1: Analysis of nitrogen isotopes}

For geochemical applications, nitrogen isotopes have historically been measured using isotope ratio mass spectrometers operated in dynamic pumping mode (e.g., ref. 87). However, since this technique is not suitable for the analysis of low nitrogen abundances, higher-sensitivity noble gas mass spectrometers operated under static vacuum conditions are now the standard method to determine the techniques such as crushing, laser ablation, laser-, or furnace-heating, and purified from interfering carbon compounds - is analyzed in the form of $\mathrm{N}_{2}$ at masses $28\left({ }^{14} \mathrm{~N}^{14} \mathrm{~N}\right), 29\left({ }^{14} \mathrm{~N}^{15} \mathrm{~N}\right)$ and $30\left({ }^{15} \mathrm{~N}^{15} \mathrm{~N}\right)$ in mono- or multi-collection mode. Measured peak heights and isotope ratios must be corrected for isobaric mass interferences from $\mathrm{CO}, \mathrm{N}_{2} \mathrm{H}$, and hydrocarbons $\left(\mathrm{C}_{2} \mathrm{H}_{\mathrm{x}}\right)$, which are ubiquitously present in the mass spectrometer system, and the instrumental precision and reproducibility is monitored by repeat analysis of atmospheric $\mathrm{N}_{2}$.

Secondary ionization mass spectrometry (SIMS) analysis represents a non-destructive means to determine $\mathrm{N}$ isotope variations with a high lateral resolution (i.e., at a scale as small as $\leq 10 \mu \mathrm{m}$ ) or a high depth resolution (i.e., $\leq 10 \mathrm{~nm}$; Fig. B1; ref. 39). While the isotope analysis of nitrogen by SIMS is challenging due to its low ionization efficiency, an intense $\mathrm{CN}^{-}$signal is formed in the presence of carbon by bombardment of the sample surface with a $\mathrm{Cs}^{+}$ion beam, and nitrogen isotope ratios have successfully been determined in the form of ${ }^{12} \mathrm{C}^{15} \mathrm{~N}^{-} /{ }^{12} \mathrm{C}^{14} \mathrm{~N}^{-}$in various extraterrestrial samples ${ }^{24,28,41,56,57,75}$ as well as in terrestrial diamonds ${ }^{90}$. Furthermore, the nitrogen isotope composition of solar wind collected during NASA's Genesis mission was determined with high precision by SIMS 31. Notably, since the ionization rate depends on the sample matrix, using a standard made of the same material as the sample and with a known $\mathrm{N}$ abundance and isotope composition is critical for an accurate measurement by this technique.

High-resolution radio and optical spectroscopy represents the only analytical means to remotely determine the isotopic composition of cometary (atmospheric) nitrogen. Cometary emissions are produced by absorption of solar light by the various molecules followed by re-emission of lines of specific wavelengths, a process called resonance-fluorescence. Isotope ratios $\left({ }^{14} \mathrm{~N} /{ }^{15} \mathrm{~N}\right)$ are determined by comparing the observed molecular spectra with synthetic spectra of the same species. Such measurements require high signal-to-noise spectra together with a high spectral resolution, and have so far only been feasible for nitrogen in the form of $\mathrm{CN}, \mathrm{HCN}$, and $\mathrm{NH}_{3}$ for a limited number of Oort cloud and Jupiter family comets. Notably, the Rosetta Orbiter Spectrometer for Ion and Neutral Analysis (ROSINA) on board the Rosetta spacecraft has been able to determine, for the first time, the abundance of $\mathrm{N}_{2}$ in-situ in the coma of comet 67P/Churyumov-Gerasimenko ${ }^{91}$. 


\section{Box 2: Possible origin(s) of the ${ }^{15} \mathrm{~N}$-enrichment in solar system material}

Two different processes are advocated to explain the ${ }^{15} \mathrm{~N}$ enrichment in solar system material. In molecular clouds, and/or in the cold regions of the disk surrounding the protostar. The possibility of ${ }^{15} \mathrm{~N}$ fractionation has been established experimentally ${ }^{92}$. Elemental ${ }^{15} \mathrm{~N}$ reacts with ${ }^{14} \mathrm{~N}_{2} \mathrm{H}^{+}$, which recombines to give ${ }^{15} \mathrm{~N}$-rich ${ }^{14} \mathrm{~N}^{15} \mathrm{~N}$. $\mathrm{He}^{+}$releases additional ${ }^{15} \mathrm{NH}^{+}$, which is incorporated into $\mathrm{NH}_{3}$ and $\mathrm{NH}_{2}$. These molecules freeze out onto dust grains to yield ammonia ice rich in ${ }^{15} \mathrm{~N}$ (ref. 73). However, because nitrogen is continuously cycled between $\mathrm{N}$ and $\mathrm{N}_{2}$, backward reactions tend to limit ${ }^{15} \mathrm{~N}$ enrichments to $30 \%$ or less ${ }^{72}$. To circumvent this problem, it has been proposed (ref. 73) that coupling between $\mathrm{N}$ and $\mathrm{N}_{2}$ is removed when $\mathrm{N}_{2}$ is deficient in the gas, e.g., frozen out with CO at very low temperature in dense cores, so that the extent of ${ }^{15} \mathrm{~N}$ fractionation is no longer limited and can account for the extreme ${ }^{15} \mathrm{~N}$ enrichments seen in the solar system ${ }^{5}$. Different reaction paths could also account for the large fractionation between amines (e.g., $\mathrm{NH}_{3}$ ) and nitriles (e.g., $\mathrm{NH}_{2}$ ) ${ }^{19}$. These possibilities are subject to discussion due to uncertainties in relevant chemical rates and branching ratios ${ }^{93,94}$.

Other types of models advocate photodissociation of $\mathrm{N}_{2}$ by UV light from the proto-Sun or from nearby stars. In one model, the photodissociation of ${ }^{14} \mathrm{~N}^{14} \mathrm{~N}$ saturates with respect to that of ${ }^{15} \mathrm{~N}^{14} \mathrm{~N}$, because the latter is much less abundant, and, therefore, photons with wavelengths able to dissociate ${ }^{14} \mathrm{~N}^{14} \mathrm{~N}$ get consumed at a greater rate than those photodissociating ${ }^{15} \mathrm{~N}^{14} \mathrm{~N}$. Dissociated $\mathrm{N}^{+}$recombines with surrounding atoms and ions (e.g., $\mathrm{H}$ and $\mathrm{C}$ ) to form amines and nitriles, which can then be removed from the gas by freezing out. This process, which is called self-shielding and is known to occur in dense cores, is postulated to take place in the solar nebula, and not only accounts for ${ }^{15} \mathrm{~N}$ fractionation but also for mass-independent oxygen isotope signatures ${ }^{95}$. Another model based on quantum mechanics ${ }^{96}$ is substantiated by photodissociation experiments with UV light from a synchrotron radiation source illuminating a $\mathrm{N}_{2}-\mathrm{H}_{2}$ mixture ${ }^{74}$. The produced $\mathrm{NH}_{3}$, which is frozen out onto a cold finger and analyzed for $\mathrm{N}$ isotopes, shows dramatic ${ }^{15} \mathrm{~N}$ excesses up to $12,000 \%$. Although it is not clear if these excesses are the result of a peculiar quantum effect or are due to self-shielding in the experimental reactor, this straightforward and illuminating measurement provides a quantitative case of extreme ${ }^{15} \mathrm{~N}$ enrichments in ice formed during interactions between dinitrogen and UV light in a manner reminiscent of the conditions that prevailed during early solar system evolution. In both cases, the key ingredient of the recipe is photons illuminating the PSN gas, indicating that specific environments are required in which the PSN is transparent enough to allow photons to react with gaseous molecules. Possibilities include the surfaces of the disk illuminated by the proto-Sun (Fig. B2) or by other young stars, or the outer regions of the disk illuminated by nearby stars. Once formed, amines and nitriles would then be decoupled from the gas and eventually be transported to regions where they can react with further radicals to yield ${ }^{15} \mathrm{~N}$-rich ices or organics. 
Box 3. H-N isotope co-variations in the solar system and constraints on the origin of terrestrial volatiles

Various isotope fractionation processes have been invoked to explain the hydrogen and nitrogen isotope co-variations recorded by the different solar system objects and reservoirs. The kinetic isotope fractionation line shown in Fig. B3 is an example of mass-dependent fractionation, proportional to the square root of mass; however, different mass dependencies would lead to distinct slopes. The ion-molecule isotope fractionation trend (from ref. 75) illustrates the effect of low temperature isotope exchange between organics and the protosolar gas. The D-enrichment of ordinary chondrite IOM with only slight or no concomitant ${ }^{14} \mathrm{~N}$ enrichment (yellow triangles) has been proposed to reflect isotope exchange of the molecular host with a D-rich component similar to gas phase molecules observed in dense clouds, pre-stellar cores and class 0 protostars ${ }^{75}$. In contrast, the ${ }^{15} \mathrm{~N}$ enrichments above the kinetic isotope fractionation line require preferential $\mathrm{N}$ isotope fractionation compared to $\mathrm{D} / \mathrm{H}$. This could result from photodissociation of protosolar $\mathrm{N}_{2}$ by UV light ${ }^{74}$, or from self-shielding ${ }^{95}$ (Box 2), and appears to have occurred within the first few tens to hundreds thousands of years after solar system formation ${ }^{71}$. Similarly, the enrichment in the heavy isotopes of oxygen $\left({ }^{17} \mathrm{O}\right.$ and $\left.{ }^{18} \mathrm{O}\right)$ relative to the composition may be the result of illumination of the PSN gas by solar/stellar photons (e.g., ref. 95). This process, which has been advocated to explain the oxygen isotope composition of refractory phases in meteorites, might also have been rapid ( $\leq 2 \mathrm{Ma}$ ), according to the chronology recorded by these refractory phases (e.g., ref. 97).

Earth shares $\mathrm{H}$ and $\mathrm{N}$ isotope signatures with bulk chondrites (Fig. B3), whereas most comets are richer in $\mathrm{D}$ and ${ }^{15} \mathrm{~N}$. These observations suggest an asteroidal, rather than cometary, origin for terrestrial volatiles ${ }^{76,98}$. While coupled $\mathrm{H}-\mathrm{N}$ systematics provide a powerful means to trace the origin of volatiles in the inner solar system, secondary fractionation processes that lead to a preferential loss of

\section{References}

439 1. Boss, A. P. \& Goswami, J. N. in Meteorites early Sol. Syst. II (Lauretta, D. S. \& McSween, H. 
441 2. Warren, P. H. Stable-isotopic anomalies and the accretionary assemblage of the Earth 442 and Mars: A subordinate role for carbonaceous chondrites. Earth Planet. Sci. Lett. 311, $44393-100(2011)$.

444 3. Zinner, E. et al. NanoSIMS isotopic analysis of small presolar grains: Search for $\mathrm{Si}_{3} \mathrm{~N}_{4}$ 445 grains from $\mathrm{AGB}$ stars and $\mathrm{Al}$ and Ti isotopic compositions of rare presolar SiC grains. 446 Geochim. Cosmochim. Acta 71, 4786-4813 (2007).

447 4. Clayton, R. N. Isotopes: from Earth to the solar system. Annu. Rev. Earth Planet. Sci. 35, 1$448 \quad 19(2007)$.

449 5. Rodgers, S. D. \& Charnley, S. B. Nitrogen superfractionation in dense cloud cores. Mon. $450 \quad$ Not. R. Astron. Soc. 385, L48-L52 (2008).

451 6. Robert, F. The D/H ratio in chondrites. Space Sci. Rev. 106, 87-101 (2003).

452 7. Robert, F., Gautier, D. \& Dubrulle, B. The solar system D/H ratio: Observations and 453 theories. Sp. Sci. Rev. 92, 201-224 (2000).

454 8. Deloule, E., Robert, F. \& Doukhan, J. C. Interstellar hydroxyl in meteoritic chondrules: 455 Implications for the origin of water in the inner solar system. Geochim. Cosmochim. Acta $456 \quad 62,3367-3378(1998)$.

457 9. Bockelée-Morvan, D., Crovisier, J., Mumma, M. J. \& Weaver, H. A. in Comets II (Festou, M. 458 C., Keller, H. U. \& Weaver, H. A.) 391-423 (Univ. Arizona Press, 2004).

459 10. Hartogh, P. et al. Ocean-like water in the Jupiter-family comet 103P/Hartley 2. Nature $460 \quad 478,218-220(2011)$.

461 11. Altwegg, K. et al. 67P/Churyumov-Gerasimenko, a Jupiter family comet with a high D/H 462 ratio. Science 347, 1261952 (2015).

463 12. Jacquet, E. \& Robert, F. Water transport in protoplanetary disks and the hydrogen 464 isotopic composition of chondrites. Icarus 223, 722-732 (2013).

465 13. Nier, A. A redetermination of the relative abundances of the isotopes of carbon, nitrogen, 466 oxygen, argon, and potassium. Phys. Rev. 77, 789-793 (1950). 
14. Cartigny, P. \& Marty, B. Nitrogen isotopes and mantle geodynamics: the emergence of life and the atmosphere-crust-mantle connection. Elements 9, 359-366 (2013).

15. Audouze, J., Lequeux, J. \& Vigroux, L. Isotopes of carbon, nitrogen and oxygen as probes of nucleosynthesis, stellar mass losses and galactic evolution. Astron. Astrophys. 43, 71-

16. Chin, Y., Henkel, C., Langer, N. \& Mauersberger, R. The detection of extragalactic ${ }^{15 N \text { : }}$ consequences for nitrogen nucleosynthesis and chemical evolution. Astrophys. J. 512,

17. Adande, G. R. \& Ziurys, L. M. Millimeter-wave observations of $\mathrm{CN}$ and $\mathrm{HNC}$ and their ${ }^{15} \mathrm{~N}$ isotopologues: a new evaluation of the ${ }^{14} \mathrm{~N} /{ }^{15} \mathrm{~N}$ ratio across the galaxy. Astrophys. J. 744,

18. Dahmen, G., Wilson, T. L. \& Matteucci, F. The nitrogen isotope abundance in the Galaxy, I. The Galactic disk gradient. Astron. Astrophys. 295, 194-198 (1995).

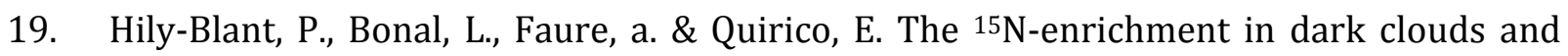

20. Bizzocchi, L., Caselli, P. \& Dore, L. Detection of $\mathrm{N}^{15} \mathrm{NH}^{+}$in L1544. Astron. Astrophys. 510, 483 L5 (2010).

21. Gerin, M. et al. Detection of ${ }^{15} \mathrm{NH}_{2} \mathrm{D}$ in dense cores: A new tool for measuring the ${ }^{14} \mathrm{~N} /{ }^{15} \mathrm{~N}$

22. Lis, D. C., Wootten, A., Gerin, M. \& Roueff, E. Nitrogen isotopic fractionation in interstellar

23. Wielen, R. \& Wilson, T. L. The evolution of the $\mathrm{C}, \mathrm{N}$, and $\mathrm{O}$ isotope ratios from an improved comparison of the interstellar medium with the Sun. Astron. Astrophys. 142, 139-142 (1997).

24. Briani, G. et al. Pristine extraterrestrial material with unprecedented nitrogen isotopic variation. Proc. Natl. Acad. Sci. U. S. A. 106, 10522-10527 (2009). 
25. Hashizume, K., Chaussidon, M., Marty, B. \& Terada, K. Protosolar carbon isotopic composition: implications for the origin of meteoritic organics. Astrophys. J. 600, 480484 (2004).

496 26. Fouchet, T. et al. ISO-SWS observations of Jupiter: measurement of the ammonia 497 tropospheric profile and of the ${ }^{15} \mathrm{~N} /{ }^{14} \mathrm{~N}$ isotopic ratio. Icarus $143,223-243$ (2000).

27. Owen, T., Mahaffy, P. R., Niemann, H. B., Atreya, S. \& Wong, M. Protosolar nitrogen. Astrophys. J. 553, L77-L79 (2001).

500 28. Meibom, A. et al. Nitrogen and carbon isotopic composition of the Sun inferred from a 501 high-temperature solar nebular condensate. Astrophys. J. 656, L33-L36 (2007).

29. Burnett, D. S. \& Genesis Sci, T. Solar composition from the Genesis Discovery Mission. Proc. Natl. Acad. Sci. U. S. A. 108, 19147-19151 (2011).

504 30. Marty, B. et al. Nitrogen isotopes in the recent solar wind from the analysis of Genesis 505 targets: Evidence for large scale isotope heterogeneity in the early solar system.

507 31. Marty, B., Chaussidon, M., Wiens, R. C., Jurewicz, A. J. G. \& Burnett, D. S. A ${ }^{15}$ N-poor 508 isotopic composition for the solar system as shown by Genesis solar wind samples. $509 \quad$ Science 332, 1533-1536 (2011).

510 32. Becker, R. H. \& Clayton, R. N. Nitrogen abundances and isotopic compositions in lunar samples. Proc. Lunar Sci. Conf. 6th 2131-2149 (1975).

512 33. Kerridge, J. F. Solar nitrogen: Evidence for a secular change in the ratio of nitrogen-15 to 513 nitrogen-14. Science 188, 162-164 (1975).

514 34. Bogard, D. D., Nyquist, L., Hirsch, W. C. \& Moore, D. Trapped solar and cosmogenic noble 515 gas abundances in Apollo 15 and 16 deep drill samples. Earth Planet. Sci. Lett. 21, 52-69 $516 \quad$ (1973).

517 35. Clayton, R. N. \& Thiemens, M. H. in Anc. Sun Foss. Rec. Earth, Moon, Meteorites (Pepin, R. 518 O., Eddy, J. A. \& Merrill, R. B.) 463-473 (Pergamon Press, 1980). 
519 36. Geiss, J. \& Bochsler, P. Nitrogen isotopes in the solar system. Geochim. Cosmochim. Acta

$520 \quad 46,529-548(1982)$.

521 37. Wieler, R. The solar noble gas record in lunar samples and meteorites. Space Sci. Rev. 85, $522 \quad 303-314$ (1998).

523 38. Wieler, R., Humbert, F. \& Marty, B. Evidence for a predominantly non-solar origin of 524 nitrogen in the lunar regolith revealed by single grain analyses. Earth Planet. Sci. Lett. $525 \quad 167,47-60(1999)$.

526 39. Hashizume, K., Marty, B. \& Wieler, R. Analyses of nitrogen and argon in single lunar 527 grains: towards a quantification of the asteroidal contribution to planetary surfaces. $528 \quad$ Earth Planet. Sci. Lett. 202, 201-216 (2002).

529 40. Füri, E., Marty, B. \& Assonov, S. S. Constraints on the flux of meteoritic and cometary 530 water on the Moon from volatile element (N-Ar) analyses of single lunar soil grains, Luna 53124 core. Icarus 218, 220-229 (2012).

532 41. Hashizume, K., Chaussidon, M., Marty, B. \& Robert, F. Solar wind record on the Moon: 533 deciphering presolar from planetary nitrogen. Science 290, 1142-1145 (2000).

534 42. Ozima, M. et al. Terrestrial nitrogen and noble gases in lunar soils. Nature 436, 655-659 $535 \quad$ (2005).

536 43. Fletcher, L. N. et al. The origin of nitrogen on Jupiter and Saturn from the ${ }^{15} \mathrm{~N} /{ }^{14} \mathrm{~N}$ ratio. $537 \quad$ Icarus 238, 170-190 (2014).

538 44. Owen, T. et al. A low-temperature origin for the planetesimals that formed Jupiter. $539 \quad$ Nature 402, 269-270 (1999).

540 45. Kerridge, J. F., Eugster, O., Kim, J. S. \& Marti, K. Nitrogen isotopes in the 74001/74002 541 double-drive tube from Shorty Crater, Apollo 17. Proc. 21st Lunar Planet. Sci. Conf 54, $542 \quad$ 291-299 (1991).

543 46. Mathew, K. J. \& Marti, K. Early evolution of Martian volatiles: Nitrogen and noble gas 544 components in ALH84001 and Chassigny. J. Geophys. Res. 106, 1401-1422 (2001). 
545 47. Hoffman, J. H., Oyama, V. I. \& von Zahn, U. Measurements of the Venus lower atmosphere 546 composition: A comparison of results. J. Geophys. Res. 85, 7871 (1980).

547 48. Alexander, C. M. O. et al. The origin of chondritic macromolecular organic matter: A $548 \quad$ carbon and nitrogen study. Meteorit. Planet. Sci. 33, 603-622 (1998).

549 49. Robert, F. \& Epstein, S. The concentration and isotopic composition of hydrogen, carbon 550 and nitrogen in carbonaceous meteorites. Geochim. Cosmochim. Acta 46, 81-95 (1982).

551 50. Kerridge, J. F. Carbon, hydrogen and nitrogen in carbonaceous chondrites: abundances 552 and isotopic compositions in bulk samples. Geochim. Cosmochim. Acta 49, 1707-1714 $553 \quad$ (1985).

554 51. Weisberg, M. et al. The CR chondrite clan. Proc. NIPR Symp. Antart. Meteorites 8, 11-32 $555 \quad$ (1995).

556 52. Grady, M. M. \& Pillinger, C. T. ALH 85085: nitrogen isotope analysis of a highly unusual 557 primitive chondrite. Earth Planet. Sci. Lett. 97, 29-40 (1990).

558 53. Prombo, C. A. \& Clayton, R. N. A striking nitrogen isotope anomaly in the Bencubbin and $559 \quad$ Weatherford meteorites. Science 230, 935-937 (1985).

560 54. Marty, B., Kelley, S. \& Turner, G. Chronology and shock history of the Bencubbin 561 meteorite: A nitrogen, noble gas, and Ar-Ar investigation of silicates, metal and fluid 562 inclusions. Geochim. Cosmochim. Acta 74, 6636-6653 (2010).

563 55. Ivanova, M. A. et al. The Isheyevo meteorite: Mineralogy, petrology, bulk chemistry, 564 oxygen, nitrogen, carbon isotopic compositions, and ${ }^{40} \mathrm{Ar}-{ }^{39} \mathrm{Ar}$ ages. Meteorit. Planet. Sci. $565 \quad 43,915-940(2008)$.

566 56. Bonal, L. et al. Highly ${ }^{15} \mathrm{~N}$-enriched chondritic clasts in the $\mathrm{CB} / \mathrm{CH}$-like meteorite 567 Isheyevo. Geochim. Cosmochim. Acta 74, 6590-6609 (2010).

568 57. Busemann, H. et al. Interstellar chemistry recorded in organic matter from primitive 569 meteorites. Science 312, 727-730 (2006). 
570 58. Aléon, J., Robert, F., Chaussidon, M. \& Marty, B. Nitrogen isotopic composition of 571 macromolecular organic matter in interplanetary dust particles. Geochim. Cosmochim. $572 \quad$ Acta 67, 3773-3783 (2003).

573 59. Nakamura-Messenger, K., Messenger, S., Keller, L. P., Clemett, S. J. \& Zolensky, M. E. 574 Organic globules in the Tagish Lake meteorite: remnants of the protosolar disk. Science $575 \quad 314,1439-1442$ (2006).

576 60. Brownlee, D. E. The Stardust mission: Analyzing samples from the edge of the solar 577 system. Annu. Rev. Earth Planet. Sci. 42, 179-205 (2014).

578 61. Brownlee, D. Comet 81P/Wild 2 under a microscope. Science 314, 1711-1716 (2006).

579 62. McKeegan, K. D. et al. Isotopic compositions of cometary matter returned by Stardust. $580 \quad$ Science $314,1724-8(2006)$.

581 63. Stadermann, F. J. et al. Stardust in Stardust - The C, N, and O isotopic compositions of 582 Wild 2 cometary matter in Al foil impacts. Meteorit. Planet. Sci. 313, 299-313 (2008).

583 64. Arpigny, C. et al. Anomalous nitrogen isotope ratio in comets. Science 301, 1522-1524 $584 \quad$ (2003).

585 65. Jehin, E., Manfroid, J., Hutsemékers, D., Arpigny, C. \& Zucconi, J.-M. Isotopic ratios in 586 comets: status and perspectives. Earth. Moon. Planets 105, 167-180 (2009).

587 66. Bockelée-Morvan, D. et al. Large excess of heavy nitrogen in both hydrogen cyanide and 588 cyanogen from comet 17P/Holmes. Astrophys. J. 679, L49-L52 (2008).

589 67. Rousselot, P. et al. Toward a unique nitrogen isotopic ratio in cometary ices. Astrophys. J. $590 \quad$ 780, L17 (2014).

591 68. Shinnaka, Y., Kawakita, H., Kobayashi, H., Nagashima, M. \& Boice, D. C. ${ }^{14} \mathrm{NH}_{2} /{ }^{15} \mathrm{NH}_{2}$ ratio 592 in comet C/2012 S1 (Ison) observed during its outburst in 2013 November. Astrophys. J. $593 \quad$ 782, L16 (2014).

594 69. Duncan, M. J. \& Levison, H. F. A disk of scattered icy objects and the origin of Jupiter595 family comets. Science 276, 1670-1672 (1997). 
70. Carusi, A., Kresák, L., Perozzi, E. \& Valsecchi, G. B. High-order librations of Halley-type 597 comets. Astron. Astrophys. 187, 899-905 (1987).

598 71. Füri, E., Chaussidon, M. \& Marty, B. Evidence for an early nitrogen isotopic evolution in 599 the solar nebula from volatile analyses of a CAI from the CV3 chondrite NWA 8616. $600 \quad$ Geochim. Cosmochim. Acta 153, 183-201 (2015).

601 72. Terzieva, R. \& Herbst, E. The possibility of nitrogen isotopic fractionation in interstellar 602 clouds. Mon. Not. R. Astron. Soc. 317, 563-568 (2000).

603 73. Charnley, S. B. \& Rodgers, S. D. The end of interstellar chemistry as the origin of nitrogen 604 in comets and meteorites. Astrophys. J. Lett. 569, L133-L137 (2002).

605 74. Chakraborty, S. et al. Massive isotopic effect in vacuum UV photodissociation of $\mathrm{N}_{2}$ and 606 implications for meteorite data. Proc. Natl. Acad. Sci. U. S. A. 111, 14704-14709 (2014).

607 75. Aléon, J. Multiple origins of nitrogen isotopic anomalies in meteorites and comets. $608 \quad$ Astrophys. J. 722, 1342-1351 (2010).

609 76. Marty, B. The origins and concentrations of water, carbon, nitrogen and noble gases on $610 \quad$ Earth. Earth Planet. Sci. Lett. 313-314, 56-66 (2012).

611 77. Füri, E., Deloule, E., Gurenko, A. \& Marty, B. New evidence for chondritic lunar water 612 from combined D/H and noble gas analyses of single Apollo 17 volcanic glasses. Icarus $613229,109-120(2014)$.

614 78. Grinspoon, D. H. Implications of the high D/H ratio for the sources of water in Venus' $615 \quad$ atmosphere. Nature 363, 428-431 (1993).

616 79. Leshin, L. A. Insights into martian water reservoirs from analyses of martian meteorite 617 QUE94201. Geophys. Res. Lett. 27, 2017-2020 (2000).

618 80. Leshin, L. A. et al. Volatile, isotope, and organic analysis of martian fines with the Mars $619 \quad$ Curiosity rover. Science 341, 1238937 (2013). 
620 81. Alexander, C. M. O., Fogel, M., Yabuta, H. \& Cody, G. D. The origin and evolution of 621 chondrites recorded in the elemental and isotopic compositions of their macromolecular 622 organic matter. Geochim. Cosmochim. Acta 71, 4380-4403 (2007).

623 82. Macy, W. \& Smith, W. H. Detection of HD on Saturn and Uranus, and the D/H ratio. 624 Astrophys. J. 222, L73 (1978).

625 83. Mahaffy, P. R., Donahue, T. M., Atreya, S. K., Owen, T. C. \& Niemann, H. B. Galileo probe 626 measurements of D/H and ${ }^{3} \mathrm{He} /{ }^{4} \mathrm{He}$ in Jupiter's atmosphere. Space Sci. Rev. 84, 251-263 (1998).

84. Niemann, H. B. et al. Composition of Titan's lower atmosphere and simple surface volatiles as measured by the Cassini-Huygens probe gas chromatograph mass spectrometer experiment. J. Geophys. Res. 115, E12006 (2010).

85. Ceccarelli, C. et al. in Protostars Planets VI (Beuther, H., Klessen, R., Dullemond, C. \& 632 Henning, T.) (University of Arizona Press, 2014).

86. Manfroid, J. et al. The CN isotopic ratios in comets. Astron. Astrophys. 503, 613-624 (2009).

87. Javoy, M. \& Pineau, F. The volatiles record of a "popping" rock from the Mid-Atlantic Ridge at $14^{\circ} \mathrm{N}$ : chemical and isotopic composition of gas trapped in the vesicles. Earth

88. Hashizume, K. \& Marty, B. in Handb. stable Isot. Anal. Tech. (de Groot, P. A.) 361-375 (Elsevier Science, 2004).

640 89. Barry, P. H., Hilton, D. R., Halldórsson, S. A., Hahm, D. \& Marti, K. High precision nitrogen 641 isotope measurements in oceanic basalts using a static triple collection noble gas mass

643 90. Hauri, E. H., Wang, J., Pearson, D. G. \& Bulanova, G. P. Microanalysis of $\delta^{13} \mathrm{C}$, $\delta^{15} \mathrm{~N}$, and N 644 abundances in diamonds by secondary ion mass spectrometry. Chem. Geol. 185, 149645 163 (2002). 
91. Rubin, M. et al. Molecular nitrogen in comet 67P/Churyumov - Gerasimenko indicates a

647 low formation temperature. Science (2015).

648 92. Adams, N. G. \& Smith, D. ${ }^{14} \mathrm{~N} /{ }^{15} \mathrm{~N}$ isotope fractionation in the reaction $\mathrm{N}^{2} \mathrm{H}^{+}+\mathrm{N}^{2}$ : 649 Interstellar significance. Astrophys. J. 247, L123-L125 (1981).

650 93. Geppert, W. D. et al. Dissociative recombination of $\mathrm{N}^{2} \mathrm{H}^{+}$: evidence for fracture of the $\mathrm{N}-\mathrm{N}$ 651

652 94. Molek, C. D., McLain, J. L., Poterya, V. \& Adams, N. G. A remeasurement of the products for 653 electron recombination of $\mathrm{N}_{2} \mathrm{H}^{+}$using a new technique: no significant $\mathrm{NH}+\mathrm{N}$ production. J. Phys. Chem. A 111, 6760-6765 (2007).

95. Clayton, R. N. Self-shielding in the solar nebula. Nature 415, 860-861 (2002).

656 96. Muskatel, B. H., Remacle, F., Thiemens, M. H. \& Levine, R. D. On the strong and selective isotope effect in the UV excitation of $\mathrm{N}_{2}$ with implications toward the nebula and Martian atmosphere. Proc. Natl. Acad. Sci. U. S. A. 108, 6020-6025 (2011).

97. Davis, A. M. et al. in Protostars Planets VI (Beuther, H., Klessen, R. S., Dullemond, C. P. \& Henning, T.) 809-831 (University of Arizona Press, 2015).

98. Alexander, C. M. O. et al. The provenances of asteroids, and their contributions to the 662 volatile inventories of the terrestrial planets. Science 337, 721-723 (2012).

\section{Additional information}

665 Correspondence and requests for materials should be addressed to B.M.

\section{Acknowledgements}

668 Discussions with Jérôme Aléon, Kathrin Altwegg, Dominique Bockelée-Morvan, Pierre 669 Cartigny, Marc Chaussidon, Kathie Mandt, Olivier Mousis, and François Robert were much 670 appreciated during the preparation of this work. This work was supported by the European

671 Research Council under the European Community's Seventh Framework Programme 
672 (FP7/2007-2013 grant agreement no. 267255 to B.M.), the Deep Carbon Observatory, and the 673 CNRS-INSU Programme de Planétologie (PNP). This is CRPG-CNRS contribution 2372. 


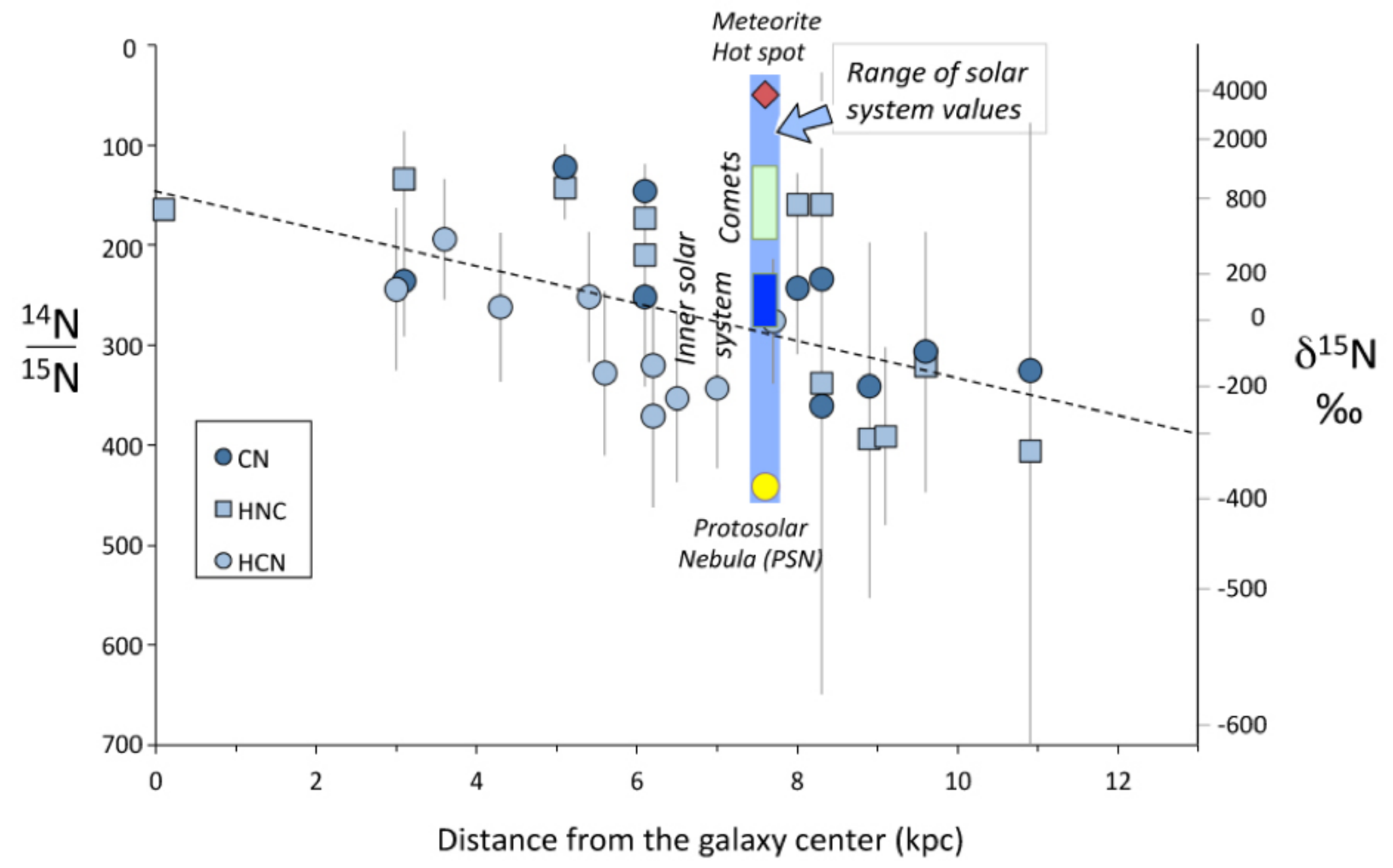




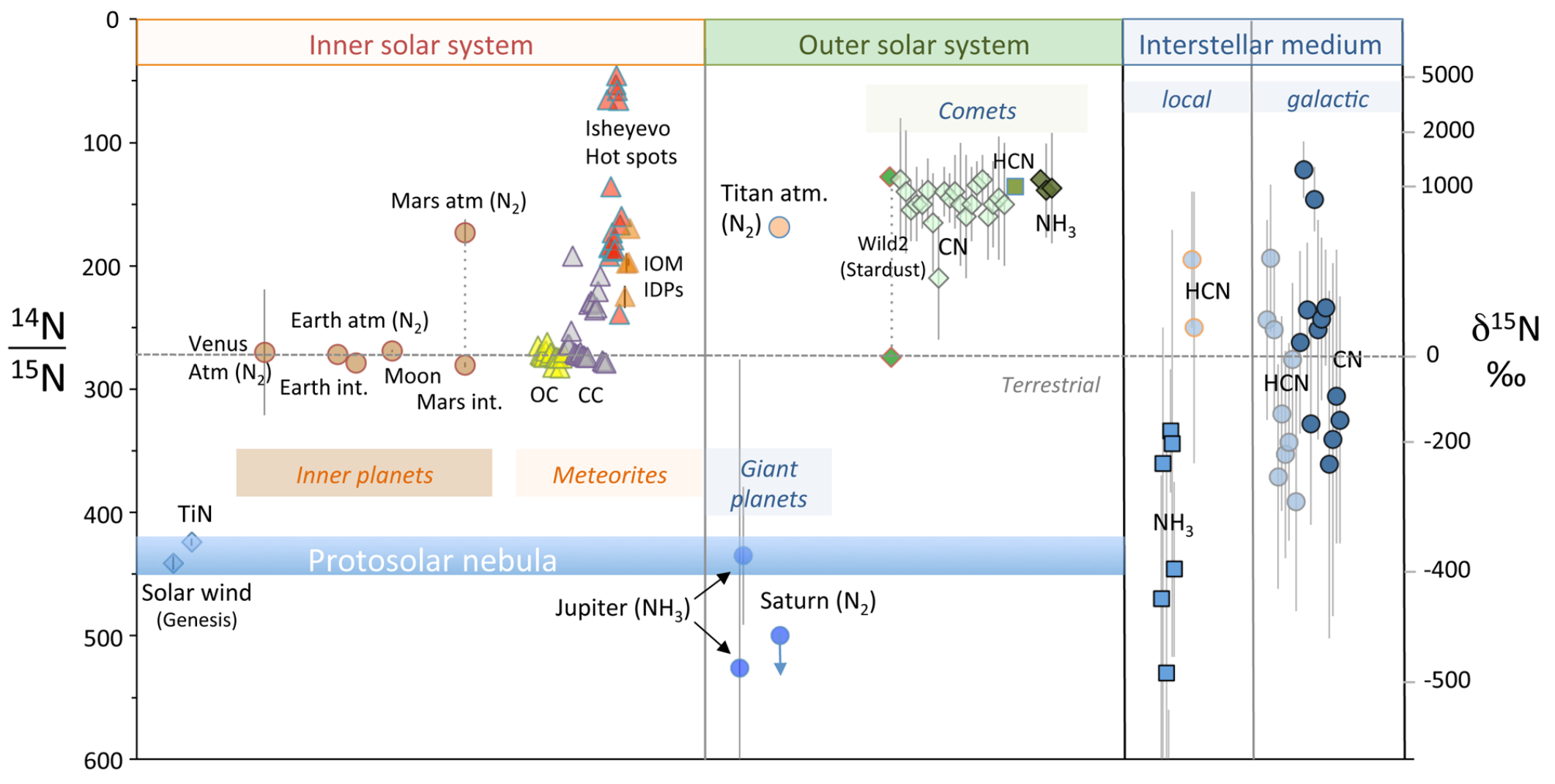




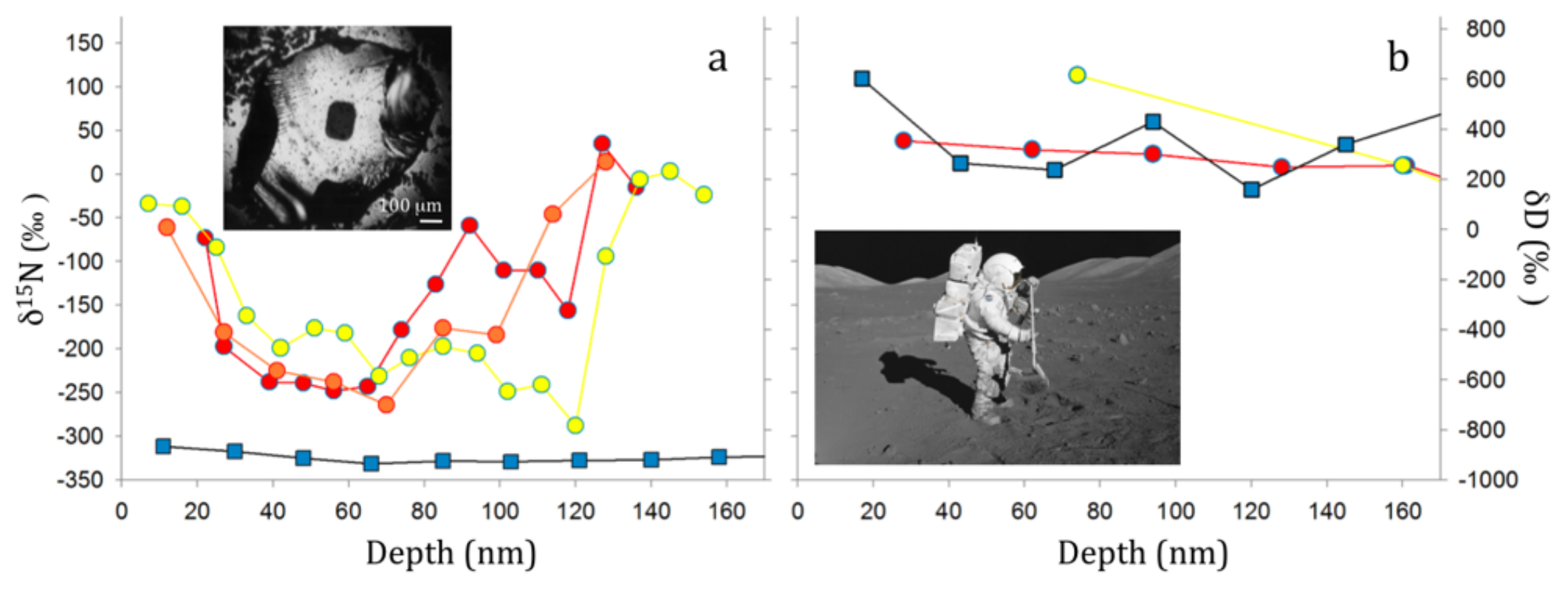




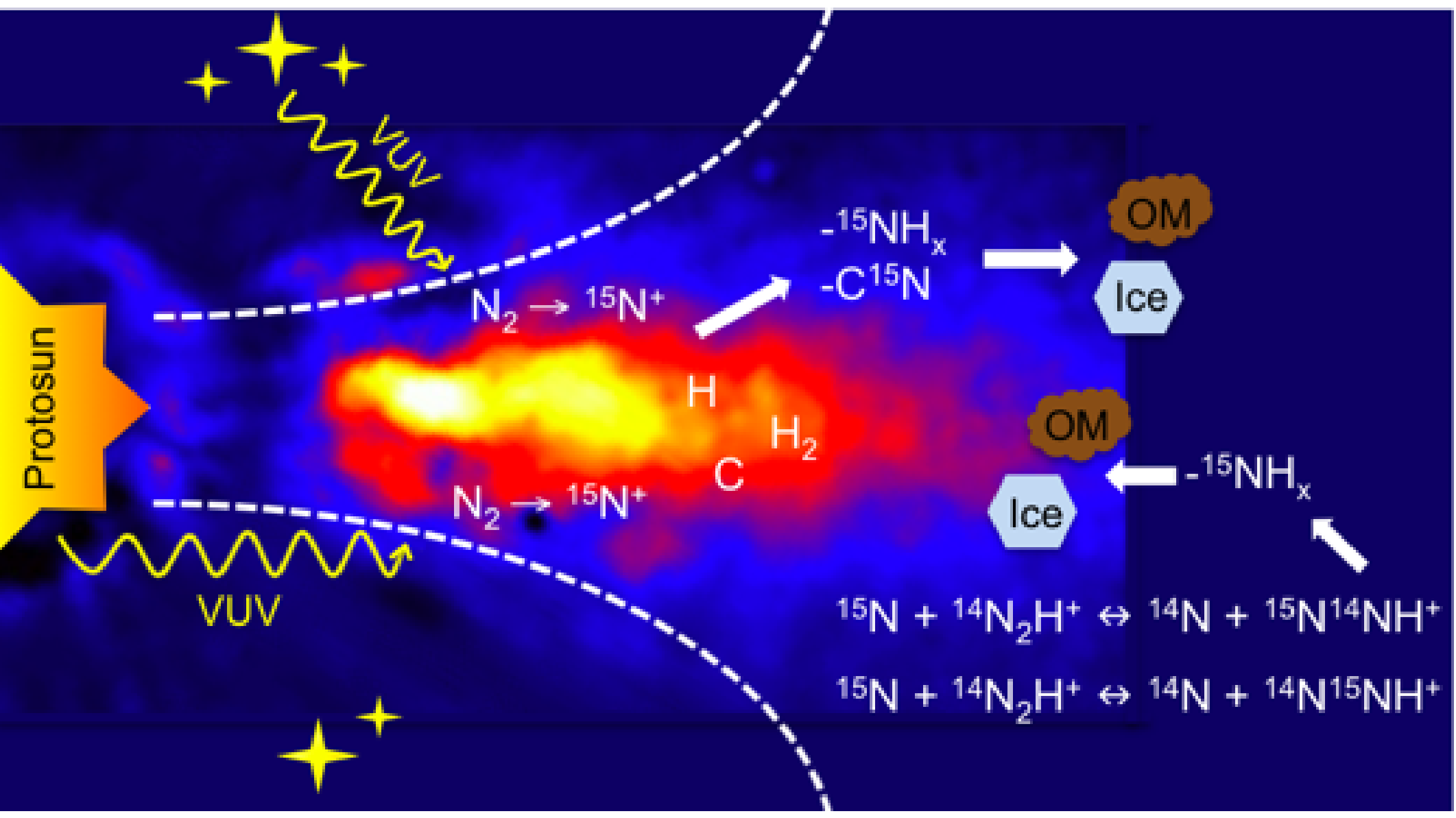


